\title{
Arbor
}

\section{La mujer en la escultura. Cuerpo y símbolo}

Javier Morales Vallejo

Arbor CLXVIII, 663 (Marzo 2001), 379-388 pp.

¿En que pensaba el tosco artista gravetiense cuando hacia el 10.000 a.C. arrancaba de las piedras las tremendas incisiones de la Venus de Lussel? ¿Que arrebato mental pudo producir aquel temblor de $44 \mathrm{~cm}$ de piedra, aquellos senos poderosos, caderas tremendas, vientre y sexo obsesivos? ¿Que significan sus manos una acariciando su vientre, guardando su secreto y la otra levantando el cuerno del gran bóvido? ¿O es quizá la luna lo que levanta?

Posiblemente es una de las primeras representaciones femeninas en escultura, continuación de las llamadas Venus paleolíticas, directas, evidentes en su cuerpo y en su símbolo. Fueron los primeros cuerpos femeninos esculpidos y los primeros símbolos de la Humanidad. Porque, ¿fue posible la Humanidad sin la mujer en la escultura, sin su cuerpo hecho símbolo?

El tema es largo y sugerente. En estas páginas no cabe sino ordenar unas cuantas intuiciones.

En primer lugar destaca la fascinación que el cuerpo de la mujer ha ejercido siempre no sólo sobre el hombre sino sobre la sociedad desde sus comienzos prehistóricos. Desde siempre se impuso su cuerpo, el volumen, la rotundidad que se puede tocar y abrazar, el cuerpo ocupando un espacio, las tres dimensiones. La imagen de la mujer fué siempre una realidad física, es decir una escultura.

$\mathrm{Y}$ al mismo tiempo, ese cuerpo físicamente venerado encarnó el misterio, la atracción sobrecogedora, algo oscuro, más allá de lo inmediato, una idea. El símbolo siempre fue indisociable del cuerpo femenino.

La Venus de Laussel encarnó la preocupación por sobrevivir, la fecundidad, el símbolo propiciatorio. La exaltación de su anatomía fue el preámbulo de las Diosas-Madre anatólicas, amasadas en barro por las manos neolíticas y alfareras del 6.000 a.C. 
En estas terracotas está el comienzo de la escultura y de la mujer en la escultura que, sea cual fuere su posterior materia definitiva — bronce o piedra-, será para siempre un barro amasado con las manos. EL agua y la tierra del barro alfarero es la esencia material de la escultura desde la prehistoria. Todos los escultores sabemos que primero es el molde en barro. El Museo C'a D'oro de Venecia muestra los bocetos en terracota de Bernini para sus grandes esculturas en piedra de Piazza Navona. Quizá con la excepción titánica de Miguel Angel, todos los escultores desde el neolítico trabajaron primero la materia creadora, el barro. Y el barro es esencialmente femenino. Por eso en el barro de estas Venus prehistóri-

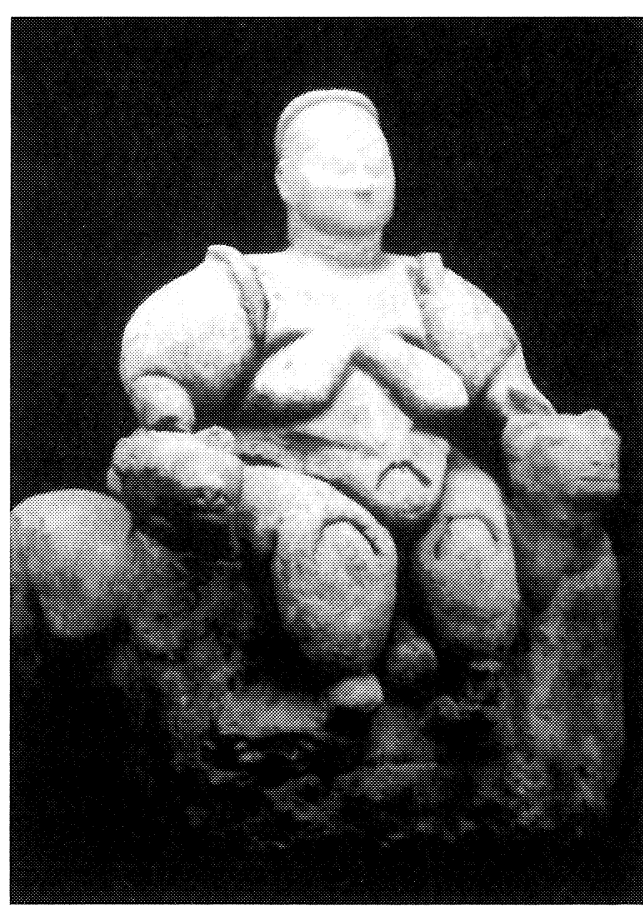

Diosa-Madre. Terracota, 6000 a.C. Museo de las civilizaciones Anatólicas. Ankara. cas está la esencia de la mujer en escultura, su cuerpo y su símbolo. El barro es tierra, lo fértil, lo inmediato, el espacio visible: la tierra es el cuerpo. Pero el barro es también el agua, símbolo de la vida, de las diosas lunares, mistéricas y acuáticas, símbolo de los meses nocturnos de la gestación y de la agricultura: los cordones umbilicales de la vida que nos unen al origen y al cosmos. El símbolo.

En segundo lugar, el sentido profundo de la mujer en la escultura está en una constante invariable: su eterna desnudez en todas las épocas y su invariable capacidad de revestirse de significados. De modo que la continua desnudez física de la mujer en la escultura queda siempre transcendida por los símbolos que encarna el modo natural. La mujer en la escultura tiende siempre a la no ocultación de su feminidad, aunque se la represente vestida, para transmitir a través de ella un mensaje implícito o explícito cuyo denominador común es la fertilidad moral, física, simbólica, filosófica. Incluso cuando el cuerpo desnudo sea considerado pecado en la cultura cristiana, María, paradigma de mujer fecunda aparecerá alimentando al Niño con su pecho desnudo. Piénsese en las abultadas vírgenes embarazadas del gótico o incluso en la Piedad vaticana de Miguel Angel con una joven María de senos maternales plenos de un sim- 
bolismo evidente. Desde las Venus paleolíticas hasta la Paulina Bonaparte, obra de Canova, en el Museo Borghese, por ejemplo, toda la escultura de mujer exalta y evidencia el cuerpo cargado de símbolos y reflexiones diversas.

Esta característica de la desnudez corporal femenina no ha sido tan compartida por la escultura del desnudo masculino, excepto la itifálica de símbolo monótono y de limitada expresión intelectual. Naturalmente hay que subrayar el gran cambio operado en la Grecia Clásica en la que los bellos y atléticos Kourós del siglo VI a.C. aparecen desnudos y frontales y cuya seguridad y aplomo simbolizaron la luz mental del orden sobre el caos y de la filosofía sobre el mito. La increíble serenidad desnuda del gran Neptuno del Museo Arqueológico de Atenas lanzando su lanza, o los guerreros de Riace, son todo un símbolo de la fuerza mental que desde el Bronce se apodera de todo el espacio que abarca la enigmática y segura luz de sus miradas.

Sin embargo las Koré femeninas del Museo del Partenón aparecen siempre transparentemente vestidas, un poco al modo egipcio. Pero siempre es la Gran Palas Athenea de Fidias la vencedora del caos y, aunque vestida, es el verdadero símbolo de la inteligencia, de la victoria definitiva sobre los oscuros temores y esclavitudes anteriores. Siempre es una mujer la que desde su corporeidad escultórica simboliza la liberación de los hombres para que puedan, desnudos, reencontrarse consigo mismos. Por eso Kourós y Korés estrenan en la escultura una insinuada sonrisa, la sonrisa ática, símbolo de la secreta alegría del descubrimiento de la autoconciencia.

La escultura desnuda femenina en Grecia llegó con todo su esplendor con las Venus de Praxíteles y posteriormente, del periodo helenístico, recuperando el lugar primordial de símbolo que habían tenido desde la prehistoria. De nuevo encarna el canon misterioso que ya no volvería a dejar en todo el arte europeo. Resucitaron en la increíble Danae de Cellini y en la Victoria de Florencia, de Giambolonia, ambos en el Museo Bargello, o en la Verdad desnuda de Bernini en el

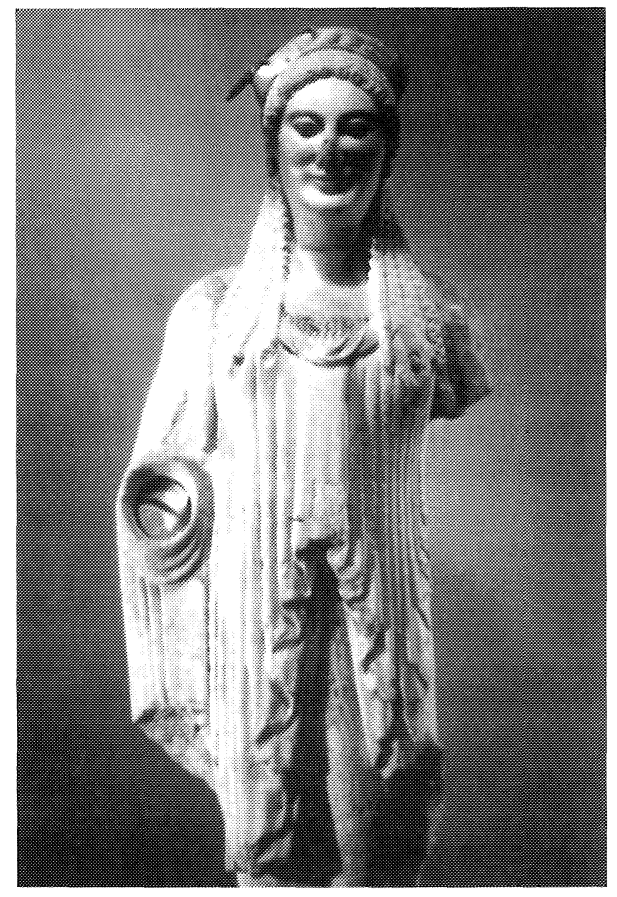

Koré. S. IV a.C. Museo de la Acrópolis. Atenas. 


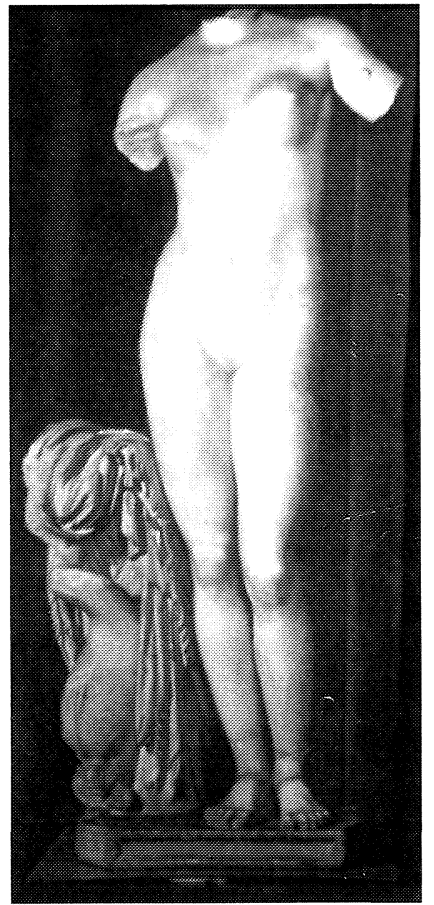

Venus de Cirene. c.315 a.C. Praxiteles. Copia helenística romana.

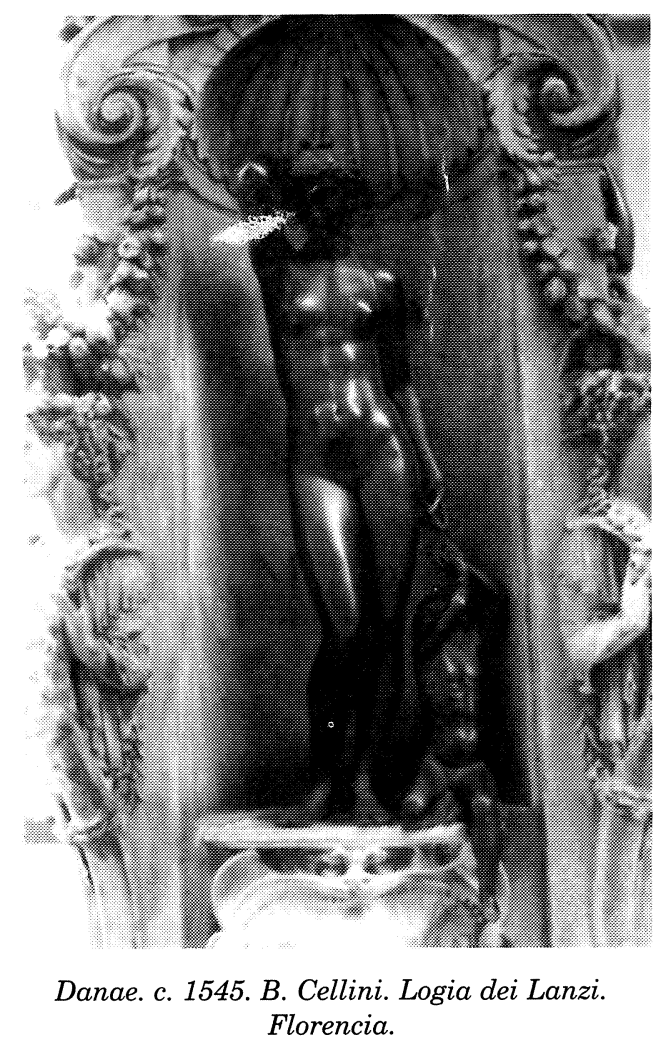

Florencia.

Borghese de Roma y cuyo precedente pictórico plasmó Julio Romano en las Estancias Vaticanas. Ejemplos estos últimos de hasta que punto el desnudo escultórico femenino expresa los símbolos difuminando su sensualidad evidente en la fuerza de una belleza evidentemente mental.

Curiosamente en la Historia del Arte cristiano occidental, el cuerpo desnudo integral masculino no ha servido como símbolo, excepto en la breve y portentosa época del primer renacimiento. Entonces el cuerpo desnudo de Cristo, como el grandioso de Miguel Angel en la iglesia romana de Sopra Minerva o el de Cellini de Felipe II en El Escorial, ambos hoy cubiertos con paños enyesados o bronces, enseñan su frontalidad viril como un símbolo del Verdadero Hombre perfecto que fue el Hijo de Dios, modelo ejemplar de la creación. Un símbolo de la belleza ideal antropocentrista y neoplatónica que sólo tuvo validez mientras duró la pureza filosófica de aquel fugaz momento. Curiosamente, también esta desnudez simbólica estuvo lógicamente acompañada por los bellísimos y delicados desnudos frontales de Jesús niño en brazos de su Madre, con el mismo significado de simbolizar al verdadero Hombre Perfecto resumen de 


\section{La mujer en la escultura. Cuerpo y símbolo}

la dignidad del hombre en cuanto tal. Así lo pintaron Rafael y Andrea del Sarto en sus conocidas pinturas del Prado, por ejemplo. Situación que, después de Trento, no se encuentra en Murillo, a pesar de ser gran pintor de Jesús niño. Las tallas de los niños Jesús virilmente completos que tanto se repitieron en el siglo XVII quizá tuvieron este mismo significado, pero siempre fueron esculturas para vestir nunca para venerar desnudas.

Pero volvamos a la mujer en la escultura, cuerpo y símbolo. Ya hemos visto que su primera característica es el valor rotundo del cuerpo que, desnudo o no, no oculta una femeneidad simbólica.

Y si no expresa directamente un símbolo como en las Venus prehistóricas sino que se trata de un retrato, en este caso la tendencia de la mujer retratada escultóricamente es ser símbolo de sí misma y de todo lo femenino, de los valores impalpables de lo femenino que se están transmitiendo desde la prehistoria.

Por ejemplo, el conocido busto de Nefertiti, hoy en Berlín: su boca carnosa, los delicadísimos planos de su rostro, su sonrisa apenas iniciada, su frente amplia, el expresivo esquema de sus ojos, su cuello esbelto, todo hace de este retrato del siglo XIV a.C. La Gioconda de la escultura. El símbolo de un misterio fascinante y ancestral.

Si contemplamos la Dama de Elche, quizá el rostro escultórico más famoso en España, nos encontramos con otro retrato: el de una gran sacerdotisa que realmente existió en el siglo IV a.C. Pero que simboliza más allá de su persona el rito femenino de la vida y es símbolo de su época matriarcal. Los bustos romanos masculinos resumen hondamente la verdad psicológica del retratado, pero los femeninos nos llevan más allá de la bografía concreta para adentrarnos en el mundo mistérico y simbólico por su propia naturaleza. Todos los retratos femeninos dejan traslucir el rostro de Isis, Perséfone o Deméter.

Toda esta enorme carga cultural de lo femenino es recogida por la escultura occidental como río de imágenes simbólicas que cada etapa cultural va modificando hasta que en el siglo XX las cosas cambian radicalmente.

Durante la Edad Media la mujer en la escultura ocupa un lugar casi exclusivo de símbolo. En los capiteles románicos la mujer real no existe. Sólo existe como imagen simbólica del mal o como imagen de las santas mujeres bíblicas. Es curioso que la imagen femenina como símbolo del mal sólo volverá a parecer otra vez en la escultura simbolista del siglo XIX, recargada de pasiones negativas, perversión, lujo embriagador y danza sensual, como las Salomés del art-decó.

A pesar de todo, la gran protagonista de la escultura medieval es la mujer: Nuestra Señora sedente con el niño y llevando pájaros, frutos y espigas en sus manos, resucita la lejana tradición iconográfica de las gran- 


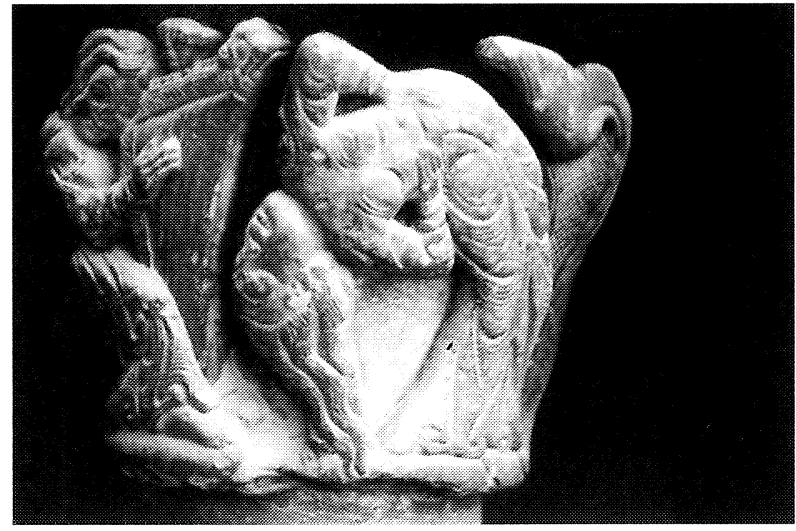

Salomé. S. XIII. Iglesia de El Salvador. Egea de los Caballeros. des diosas fértiles mediterráneas, también fuentes de la vida y en cuyo maternal regazo tiene lugar el encuentro del cielo y la tierra. Todavía hoy, profundamente cristianizadas, estas esculturas nos miran hieráticas con sus ojos grandes y sus sonrisas de enternecedor misterio, resumiendo siglos de escultura simbólica feme-

nina. Flores, frutos y pájaros en las manos y mantos policromados de estas mujeres maravillosas que han guiado a la humanidad desde que ésta se hizo agrícola, sedentaria y matriarcal.

Entrar en el antiguo refectorio de canónigos de la Catedral de Pamplona, hoy museo y cuyo púlpito de lectura muestra en sus relieves escultóricos a la doncella virgen con el unicornio -uno de los símbolos femeninos más estremecedores-; entrar en el Museo Marés de Barcelona o en la enigmática iglesia templaria de Eunate, proporciona una profunda experiencia de meditación sobre la imagen de la Mujer como símbolo mediterráneo de la Agricultura, la Fertilidad y la Naturaleza sagrada y Madre Protectora.

El Gótico amplió el campo simbólico de la mujer escultura: todas las virtudes, las ciencias, el trivium y el cuadrivium, adoptaron forma femenina que los escultores colocaron incansables sobre las rejas de los coros, como en la Catedral de Zaragoza y en los relieves de las puertas y fachadas. Las esculturas simbólicas femeninas coronaron cresterías hasta los sitios más insospechados. Los

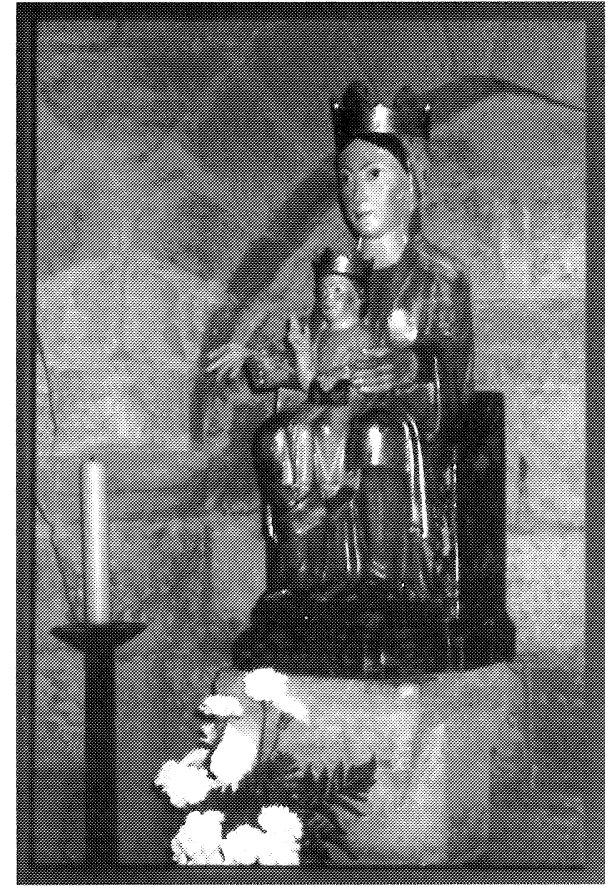

Virgen con el Niño y espigas. S. XIII. Eunate. 


\section{La mujer en la escultura. Cuerpo y símbolo}

tejados góticos de la Catedral de Milán, abiertos hoy al público, proporcionan uno de los mejores ejemplos.

La sabia sonrisa de los ángeles de Chartres, jóvenes deliciosamente femeninos, recuperan la sonrisa ática de los jóvenes Kourós griegos y enlazan con el misterio de la sonrisa etrusca de las embriagadoras mujeres modeladas en la vieja terracota de los sarcófagos del Museo Villa Julia en Roma. Vida y muerte, origen y misterio simbolizados siempre en la mujer hecha escultura. El gótico de los trovadores y de San Bernardo tomó a la mujer como símbolo de la filosofía y de la tierra desposada con la Divinidad y las esculturas del Amor inundaron Europa con una belleza filosófica, sonriente, delicada e intemporal. Es la edad de oro de la mujer en la escultura hecha puro símbolo.

El Renacimiento y el Barroco recuperaron el brillante desnudo femenino en su apogeo del mármol y bronce. La mujer en la escultura renacentista encarna símbolos de belleza desnuda que rompe los límites de lo físico hasta el asombro, tan sensualmente cercana y tan inasequible y lejana en su increíble perfección. Sólo la fuerza filosófica del neoplatonismo pudo crear los conocidos desnudos femeninos de Miguel Angel, rompiendo la barrera entre lo físico y simbólico con un resultado estremecedor.

El retrato escultórico del Renacimiento es de cuerpo solemne sirviendo de pedestal para las egregias cabezas. Las mujeres esculpidas por Leoni, como la Emperatriz Isabel del Museo del Prado y las reinas de los cenotafios del Monasterio del Escorial, son símbolos de un inmenso y tranquilo poder femenino que se sabe incontestado. El sentido de sus cuerpos maravillosamente tratados tiene la función de empujar hacia arriba y sostener la cabeza humana, sus ojos, sus pómulos y labios expresivos. El cuerpo humano renacentista ostenta su símbolo que es el rostro, la conciencia, el alma humana. En esto la escultura renacentista reinterpreta a la perfección la estatuaria griega en la que toda la arquitectura del cuerpo sirve como pedestal a la cabeza humana. Nunca la física y la metafísi-

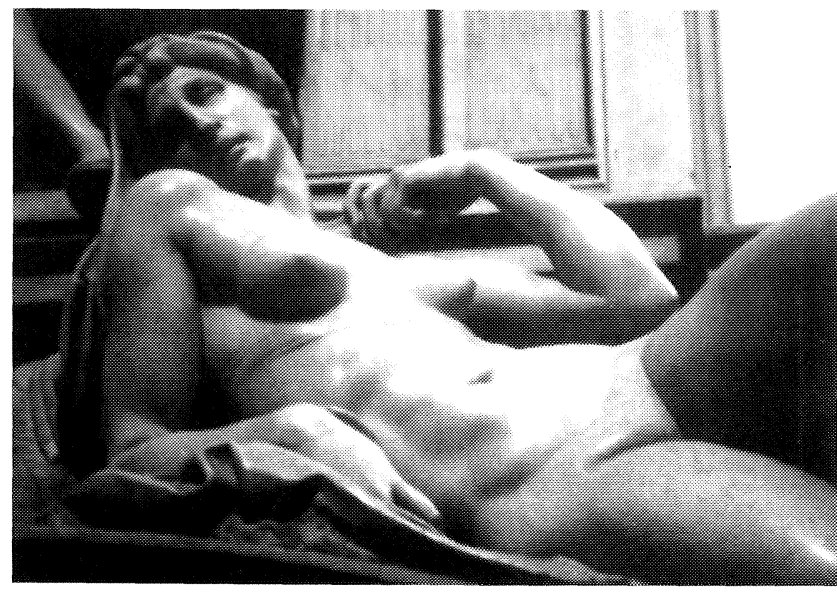

Tumba de Juliano de Medicis. «El día». c. 1530. Miguel Angel. Capilla Medicis. Florencia. 
ca se encontraron mejor tratados en una unidad.

El Barroco exalta la opulencia de los cuerpos femeninos en una apoteosis de símbolos antiguos. El cuerpo femenino barroco se reproduce incansablemente en la escultura protagonizando toda clase de ideas, símbolos, sentimientos y actitudes humanas.

Las Magdalenas barrocas de belleza mediterránea inundaron las iglesias, como la conocida escultura de Bernini en la Catedral de Pisa. Y los exuberantes símbolos de la Caridad romana adornaron cenotafios papales en el Vaticano. Los programas escultóricos del Barroco recopilaron todas las imágenes iconográficas femeninas que el mediterráneo venía produciendo desde la prehistoria.

La apoteosis de las formas y de los sentimientos pasionales tuvieron

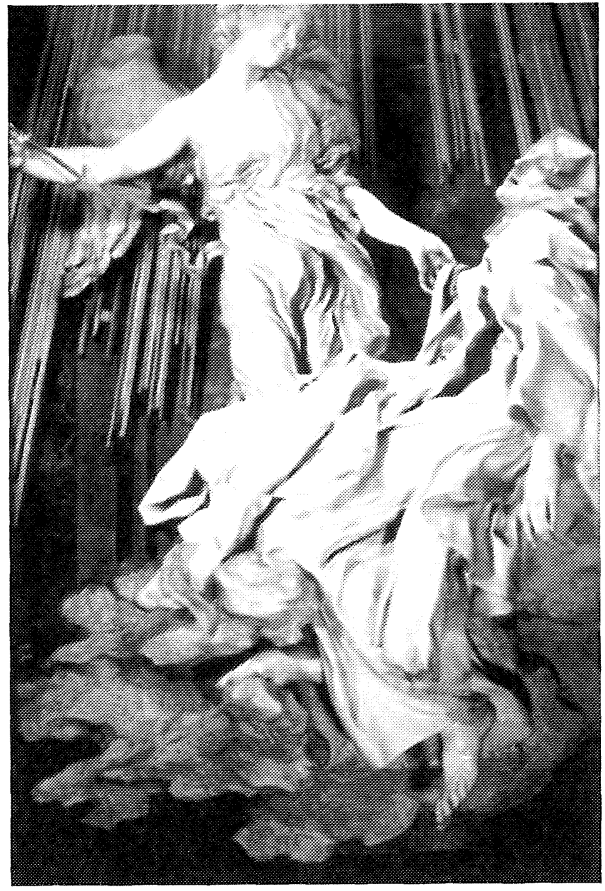

Extasis de Santa Teresa. h. 1650. Bernini. Iglesia de Santa María de la Victoria. Roma. su punto máximo en el éxtasis de Santa Teresa de la Iglesia de Sta. María de la Victoria en Roma, obra de Bernini en la que el bello ángel adolescente de profunda tensión y eterna sonrisa femenina forma contrapunto con la tensión y dulzura torturante del amor, que sólo la expresión de una mujer puede simbolizar. Resumen sabio de una larguísima tradición de la mujer en la escultura como cuerpo y cómo símbolo. Cuerpo desfalleciente y huidizo y símbolo anhelante del éxtasis teresiano.

Esta misma tensión femenina, mediterránea, ancestral y emocionante es la que Luisa Roldán, la Roldana, supo plasmar en el nacarado rostro de la Macarena de Sevilla. Verdadero icono simbólico de antiquísimas creencias religiosas, símbolo femenino de sentimientos vitales, bellos, dramáticos, reflejados en ése cuerpo, rostro de dulce llanto, boca entreabierta y manos barrocas como no pudiendo quedarse con nada porque soportan el aire de todas las cosas. En la oscuridad de cirios y muchedumbres entregadas al misterio, esta escultura de mujer encarna en su portentoso realismo mágico todas las Isis que desde siempre han arado la tierra sentimental de las primaveras mediterráneas.

Las tormentosas aguas barrocas se remansarán en la placidez lejana neoclásica donde la mujer en la escultura retoma un lugar elegante y pri- 


\section{La mujer en la escultura. Cuerpo y símbolo}

vilegiado. Antonio Canova en su «Eros besando a Psique», 1790, en el Museo del Louvre, reproduce la sonrisa angélica, femenina, etrusca y berniniana llena de misterio simbólico, arrebatando con su beso mágico la luz de los ojos femeninos entornados. Otra vez la mujer de bellísimo cuerpo hecha escultura simbólica de su propia poesía.

El neoclasicismo reproduce una mujer-escultura de finísimo dibujo de contornos sinuosos, sensuales y pliegues griegos que Fidias nunca hubiese pensado. La mujer en la escultura neoclásica es el símbolo de la elegancia transparente y tiene cuerpo de adolescente, muy lejos de las rotundidades anteriores. Es más propio de nieblas centroeuropeas que de soles mediterráneos. Su símbolo es algo desfallecente, huidizo, ideal, romántico, irreal. La Hebe del Casón del Buen Retiro, otro Cánova, se nos muestra danzari-

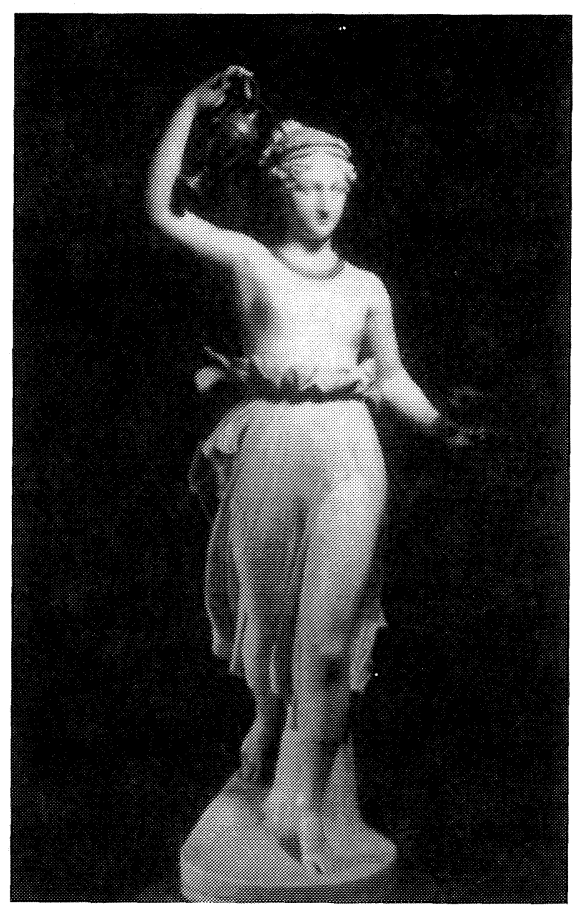

Hebe. c. 1790. A. Canova. Casón del Buen Retiro. Museo del Prado.

na, leve y aérea, encarnando un símbolo tan grato como impreciso. Es quizá sólo la elegancia formal propia de la estética de su tiempo. Pero esta mujer - niña es tan perfecta en su risueña y ambigua seguridad que ejerce la fascinación del ensueño y de la armonía alejada de todo contacto con la realidad. Símbolo en estado puro.

El Romanticismo es inevitablemente una advocación grandilocuente. La mujer en la escultura ocupa un notorio doble lugar: como retrato nos presenta mujeres ampulosas y rebosantes de su propia naturaleza. Cómo símbolos, todos los frisos se llenan de llamativas mujeres-matronas, henchidas y algo redundantes en su locuacidad de préstamos iconográficos. Enormes capiteles de rostro femenino nos observan. Pero el meritorio esfuerzo del dibujo académico no logra quizá despertar la espontaneidad de la vida fértil y misteriosa que encarna la cuerpo de la mujer en la escultura de otras épocas.

Finalizando el siglo XIX surge el vuelco mediterráneo en la escultura de la mano de Rodin y Bourdelle. Su fascinación por el cuerpo humano produce una escultura desnuda, llena de energía, de rebuscada naturalidad y apasionamiento. La mujer en la escultura ocupa un lugar privile- 


\section{Javier Morales Vallejo}

giado que recoge todas las tensiones masculinas, todos sus temores y ansiedades. La mujer en su escultura es el mito del hombre, es una mujer algo irreal, aunque sea fuerte, musculosa, fibrosa. Pero está trabajada casi siempre como contrapunto a la metafísica atormentada existencial masculina. El cuerpo de la mujer vuelve a ser símbolo sentimental e inmenso receptáculo esculpido, amor inasequible, poesías huidiza, madre naturaleza que sostiene el llanto del hombre, su fantasía y sus mitos.

La mujer en la escultura de Maillot, es a mi juicio, el último latido realmente mediterráneo despojado de adjetivos y mitos superfluos. Son cuerpos femeninos, rotundos, soleados, fecundos, de fuertes caderas, senos y músculos poderosos, que evocan aquellas Venus prehistóricas.

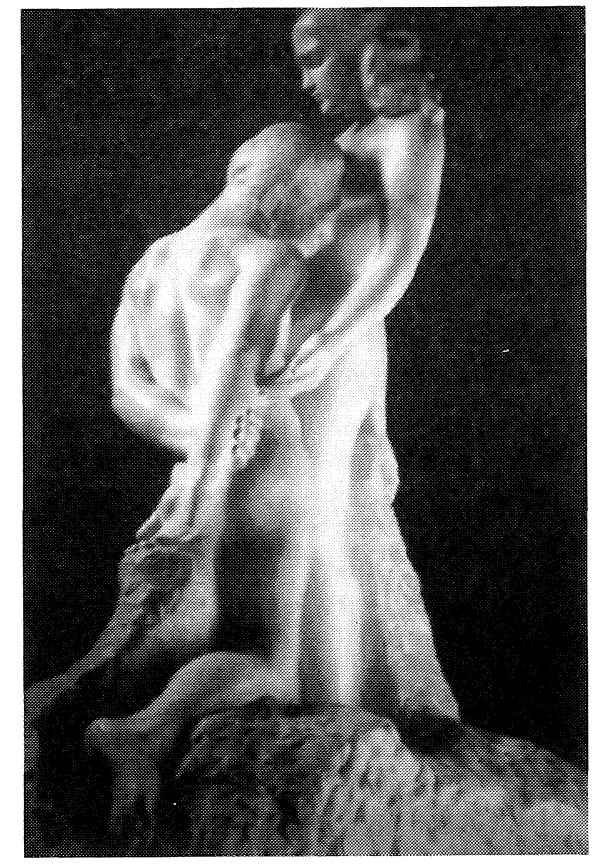

El retorno del ídolo. 1889. A. Rodin. Museo Rodin. París.

A través de miles de años estas Venus recuperan aquí la honda identidad simbólica de la mujer. Es una escultura de espléndido dibujo donde el gran mito de la mujer-naturaleza se desvela sin mitologías. Y el latido de bronce de sus vientres fértiles se ofrece de nuevo como un laico espacio sagrado donde vuelven a encontrarse los cielos y las tierras. Donde la vida asombra a las propias mujeres y vuelve a subyugar a los hombres. Estas últimas esculturas representan el eterno retorno de las lunas de agua y de las nocturnidades de Demeter y Cibeles. Son cuerpos de mujer ofrecidos al sol y al aire libre. Pero su pasmosa rotundidad femenina las hace mujeres esenciales, mujeres relegadas al eterno femenino mediterráneo que, desde siempre, han ofrecido su cuerpo como símbolo inagotable del misterio de la vida.

Todo lo que vino después es otra historia.

NOTA: Naturalmente no he pretendido el rigor de un esquema histórico, ni siquiera aproximado. Pero a veces las impresiones personales y las sugerencias culturales ayudan a comprender y expresar uno de los temas más apasionantes y difíciles de condensar en el Arte, como es la relación entre el cuerpo sorprendente y la mente insoldable. 